astronomy we have never found a comet's tail really as long as this.

I leave out the detailed description of the comet's aspect, because NATURE has given full accounts and sketches, and I come to the most interesting part of $M$. Schiaparelli's lecture, on the production of those magnificent phenomena. I translate literally from Signor Schiaparelli's manuscript.

The proper nucleus of the comet is a solid or liquid body so small as rarely to be seen : in the greater number of comets, as in this, it seems to be not large enough to be visible even in powerful telescopes. It seems also that in some comets there are several nuclei, very small and close, whose particular atmospheres in their development at last unite in one. As long as such a body (or system of bodies) rem ins far from the sun, in extraplanetary regions, where temperature is less than $-140^{\circ} \mathrm{C}$. (according to the most moderate estimates), and where the sun has perhaps no power to heat it, the matter must be wholly solid or at least liquid; and, if a small quantity is gaseous or vaporous, it must have a great density and a small volume. The progressive approach to the sun by its descending orbit will obviously swell the enveloping atmosphere, or give rise to one if it does not yet exist, with materials generated by the surface. Shortly the nucleus begins to appear surrounded by a blaze of light, feeble at first, but afterwards more and more brilliant, which is the star or head of the comet. Many comets do not go beyond this first phase, both because they have not matter enough to make an atmosphere, and because they do not come near enough to the sun to be subject to a great ineat. Some comets do not enter the earth's orbit, others cannot reach that of Mars, and we know that the comet of 1729 got only a little way into the orbit of Jupiter. The most part of those comets, being exposed very moderately to the solar influence, cannot increase, and remin telescopic; and it is very probable that a large number stop at Jupiter or Saturn's orbit (or even further) in their descent upon the sun : none of those are seen, and we can speak of them only by conjecture.

When a comet, however, as the present, pierces through the interior part of the planetary system, it is in the best condition to develop its atmosphere if it contain matter enough to do so. But the sun, while attracting to himself the nucleus, has the property to repel some of the matter of the atmosphere. It is not well known how and why this matter is repelled, and to expound the various hypotheses on this point would take too long a time. The effect of repulsion is nevertheless undoubted, and manifested by the fact that those parts of the cometary atmosphere, under the sun's impulse, almost as if under a gale blowing from it, leave the nucleus and fly in an opposite direction away from the sun, producing the tail, which, nourished successively by incessant evaporations of the nucleus, more and more increases in length, till the atmosphere of the nucleus, wholly repelled, overflows into the tail, and thus exhausts itself. This happens usually when the nucleus, after the perihelion, receding from the sun and being then exposed again to the cosmical cold, is no longer able to supply with new evaporations the part of the atmosphere which the tail absorbs. Deprived thus of its former envelopes, and unable to engender others, the nucleus is reduced again to itself, and the comet disappears.

The tail of the comet consists then of matters repelled by the sun with a mysterious power. But, during the above described period of conflagration, other interesting events occur in the comet. It is so much swollen and convulsed by solar heat that the little nucleus is not able sometimes to keep together the fragments by its own very feeble attraction. Violent eruptions take place at the surface, so that pieces of nucleus are raised and thrown out of the principal body's attraction. Those fragments then pass through the heavens as independent bodies, and their orbits are not very different from the orbit of the nucleus. Sometimes one of the broken pieces is great enough to engender another separate comet: that is, the several times observed phenomenon of a divided comet. But most generally it seems that separated pieces are very small and numerous, like the sparks of a piece of salt thrown on the fire; and extend along the trajectory of the nucleus like a current or projection of corpuscles, which gradually invade all the orbit of the comet. Many comets (probably all) engender in their course a similar retinue; and the planetary intervals are peopled by those corpuscles produced by a comet's partial disintegration. When the earth in its yearly revolution passes through one of these processions it meets with several pieces, which get inflamed by contact with the terrestrial atmosphere, and burn in a very short time, producing a falling star.

An example of such a process of separation was given by the present comet. In effect, a little before October 15 M. Schmidt, the astronomer at Athens, observed an irregular and very feebly shining thin cloud leaving the comet, withdrawing, and finally disappearing. It was more dense and luminous in some places than in others, but it looked not like a comet, having rather the aspect of a mass of corpuscles exploded by the principal nucleus. The atmosphere also enveloping the principal nucleus offered analogous phenomena, being not round and symmetrical, but lengthened spindle-fashion, with several more luminous centres of different intensity spread in an oval cloud. We have, besides, reason to believe that another little comet, which was observed in the beginning of 1880 in the austral regions of the earth, running in an orbit very similar, was previously separated from our great comet.

M. Schiaparelli passed afterwards to another question, on the chemical constitution of comets, explaining the principle of spectrum analysis and its application to celestial chemistry. He remarked that the present and Wells's comet only, by their coming so near the sun, could present the lines of sodium, whilst all the comets before observed gave only lines of hydrocarbons in the spectroscope; and it is very probable, according to modern theories, that comets contain also some matters which are made apparent in falling stars and in aërolites, as iron, nickel, silicium, magnesium, aluminium, and others. This confirms the induction as to the similarity of their chemical composition to that of the earth; and the common origin of comets in the planetary system is evidently proved by their accompanying the sun in its progressive movement towards the constellation of Hercules. It seems that comets belonging to the solar system would have the function of continually dissipating matter in space, as a compensation to the attractive power of the greatest centre, the sun.

Pressure of space obliges me to leave out the very eloquent conclusion of this lecture, in which the lecturer refuted the apprehensions as to the shock of a comet with the earth, and its probable consequences, discussing the great moral importance of these studies as an antidote to the fears and superstitions of ignorant people. Referring to Anaxagoras and Galileo, he concluded with these words: "A science which suffered such noble condemnations, and is able to awake such noble hopes, cannot be considered as futile and idle; it will always be dear to the friends of truth; dear to every one who is convinced that man lives not by bread alone." FrANCIS PORRO

R. Observatory of Brera in Milan

\section{THE SOARING OF BIRDS}

THE recent correspondence in NATURE upon this subject ought not to close without some reference to a possible explanation of soaring which does not appear to have been yet suggested. 
I premise that if we know anything about mechanics it is certain that a bird without working his wings cannot, either in still air or in a uniform horizontal wind, maintain his level indefinitely. For a short time such maintenance is possible at the expense of an initial relative velocity, but this must soon be exhausted. Whenever therefore a bird pursues his course for some time without working his wings, we must conclude either (I) that the course is not horizontal, (2) that the wind is not horizontal, or (3) that the wind is not uniform. It is probable that the truth is usually represented by (I) or (2); but the question I wish to raise is whether the cause suggested by (3) may not sometimes come into operation.

In NATURE, vol. xxiii. p. Io, Mr. S. E. Peal makes very distinct statements as to the soaring of pelicans and other Targe birds in Assam. The course is in large and nearly circular sweeps, and at each lap some Io or 20 feet of elevation is gained. When there is a wind, the birds may in this way "without once flapping the wings" rise from a height of 200 to a height of 8000 feet.

That birds do not soar when there is no wind is what we might suppose, but it is not evident how the existence of a wind helps the matter. If the wind were horizontal and uniform it certainly could not do so. As it does not seem probable that at a moderate distance from the ground there could be a sufficient vertical motion of the air to maintain the birds, we are led to inquire whether anything can be made of the difference of horizontal velocities which we know to exist at different levels.

In a uniform wind the available energy at the disposal of the bird depends upon his velocity relatively to the air about him. With only a moderate waste this energy can at any moment be applied to gain elevation, the gain of elevation being proportional to the loss of relative velocity squared. It will be convenient for the moment to ignore the waste referred to, and to suppose that the whole energy available remains constant, so that however the bird may ascend or descend, the relative velocity is that due to a fall from a certain level to the actual position, the certain level being of course that to which the bird might just rise by the complete sacrifice of relative velocity.

For distinctness of conception let us now suppose that above and below a certain plane there is a uniform horizontal wind, but that in ascending through this plane the velocity increases, and let us consider how a bird sailing somewhat above the plane of separation, and endowed with an initial relative velocity, might take advantage of the position in which he finds himself.

The first step is, if necessary, to turn round until the relative motion is to leeward, and then to drop gradually down through the plane of separation. In falling down to the level of the plane there is a gain of relative velocity, but this is of no significance for the present purpose, as it is purchased by the loss of elevation ; but in passing through the plane there is a really effective gain. In entering the lower stratum the actual velocity is indeed unaltered, but the velocity relatively to the surrounding air is increased. The bird must now wheel round in the lower stratum until the direction of motion is to windward, and then return to the upper stratum, in entering which there is a second increment of relative velocity. This process may evidently be refeated indefinitely; and if the successive increments of relative velocity squared are large enough to outweigh the inevitable waste which is in progress all the while, the bird may maintain his level, and even increase his available energy, without doing a stroke of work.

In nature there is of course no such abrupt transition as we have just now supposed, but there is usually a continuous increase of velocity with height. If this be sufficient, the bird may still take advantage of it to maintain or improve his position without doing work, on the principle that has been explained. For this purpose it is only necessary for him to descend while moving to leeward, and to ascend while moving to windward, the simplest mode of doing which is to describe circles on a plane. which inclines downwards to leeward. If in a complete lap the advantage thus obtained compensates the waste, the mean level will be maintained without expenditure of work; if there be a margin, there will be an outstanding gain of level susceptible of indefinite repetition.

$A$ priori, I should not have supposed the variation of velocity with height to be adequate for the purpose; but if the facts are correct, some explanation is badly wanted. Mr. Peal makes no mention of the circular sweeps being inclined to the horizon, a feature which is essential to the view suggested. It is just possible, however, that the point might escape attention not specially directed to it.

However the feat may be accomplished, if it be true that large birds can maintain and improve their levels without doing work, the prospect for human flight becomes less discouraging. Experimenters upon this subject would do well to limit their efforts for the present to the problem of gliding or sailing through the air. When a man can launch himself from an elevation and glide long distances before reaching the ground, an important step will have been gained, and until this can be done, it is very improbable that any attempt to maintain the level by expenditure of work can be successful. Large birds cannot maintain their levels in still air without a rapid horizontal motion, and it is easy to show that the utmost muscular work of a man is utterly inadequate with any possible wings to allow of his maintenance in a fixed position relatively to surrounding air. With a rapid horizontal motion, the thing may perhaps be possible, but for further information bearing upon this subject, I must refer to a paper on the resistance of fluids published in the Philosophical Magazine for December, 1876.

$$
\text { March } 22
$$

RAYLEIGH

\section{PHILIP CHRISTOPH ZELLER}

F NTOMOLOGY has just sustained an irreparable loss by the death of Prof. Zeller, which took place at Grünhof, near Stettin, on March 27, suddenly, from heart disease. Zeller was born on April 9, 1808, at Steinheim, in Württemburg. For many years he was attached to official educational establishments in Germany, especially at Glogau in Silesia, and Meseritz in Posen. While at the former place the honorary title of Professor was bestowed upon him by the Government on account of his eminent scientific researches, and some time afterwards he retired from official duties, and settled near Stettin, where much of his leisure was devoted to the Entomological Society that has its headquarters in that town, of which he was acting secretary, and of which Dr. C. A. Dohrn is president. Zeller's fame as an entomologist is more especially based upon his publications on Lepidoptera, more particularly of Europe, and chiefly on the smaller moths. His first recorded paper appeared in Oken's Isis for 1838 , and consisted of a critical determination of the Lepidoptera in Réaumur's "Memoirs," a prize essay, in which the author took first place. From that time a continuous stream of valuable papers by him appeared, and on the day of his death he was engaged in scientific work. It is utterly impossible to give here even the titles of his more important works. It is with regret that we are obliged to admit that the title of "entomologist" does not always enable us to take for granted that the entomologist is also a naturalist. Zeller was both, in the fullest acceptation of the terms. While his purely descriptive work is of the highest character, his investigations into the natural history of his subject were persistent, and he never ceased to deprecate the "slop-work" so painfully evident in the writings of some entomologists. For many years he made almost annual excursions in pursuit of his favourite science, especially in the Alps of Central 